Copyright $\odot 2015$ The Author(s). Published by BCS, The Chartered Institute for IT under Creative Commons license http://creativecommons.org/ licenses/by/4.0/

\section{In this issue: Time to replace doctors' judgement with computers}

\author{
Simon de Lusignan \\ Editor-in-Chief of Journal of Innovation in Health Informatics \\ Professor of Primary Care and Clinical Informatics, \\ University of Surrey, Guildford UK
}

\begin{abstract}
Informaticians continue to rise to the challenge, set by the English Health Minister, of trying to replace doctors' judgement with computers. This issue describes successes and where there are barriers. However, whilst there is progress this tends to be incremental and there are grand challenges to be overcome before computers can replace clinician. These grand challenges include: (1) improving usability so it is possible to more readily incorporate technology into clinical workflow; (2) rigorous new analytic methods that make use of the mass of available data, 'Big data', to create real-world evidence; (3) faster ways of meeting regulatory and legal requirements including ensuring privacy; (4) provision of reimbursement models to fund innovative technology that can substitute for clinical time and (5) recognition that innovations that improve quality also often increase cost. Informatics more is likely to support and augment clinical decision making rather than replace clinicians.
\end{abstract}

\section{TIME TO REPLACE DOCTORS' JUDGEMENT WITH MORE COMPUTERS}

As I write 'In this issue' - the English Health Secretary announces that it is time to replace doctors' judgement with computers. ${ }^{1}$ In one sense, this is complete nonsense, but in another, this issue of the Journal of Innovation in Health Informatics suggests areas where informaticians might chip away at this goal. Experience tells us that this goal will not be achieved any time soon, but the goal of informatics is to support the clinical process and provide analyses beyond those that the human brain can possibly process.

\section{COMPUTERISED SYSTEMS DETECT CHANGE THAT HUMANS MISS}

Our first paper reports how weight loss, often an important sign of ill health, was missed by humans but picked up by computerised review. ${ }^{2}$ The second paper in this issue reports that even when tools are provided to assess risk in chronic disease that primary care professionals adopted only those, they found usable and credible. ${ }^{3}$ This paper discusses the challenge of integrating technology into clinical workflow, a theme I will return to later. A later paper in this issue reports how a self-service kiosk diagnoses depression and other mental health problems. ${ }^{4}$ This might well meet the English Health Secretary's needs, and could perhaps replace doctors' judgement? 


\section{BARRIERS TO REPLACING OLD PROCESSES WITH COMPUTERS}

A paper from Canada sets out the barriers to implementing e-prescribing; these include legal and regulatory, system integration and insensitivity to local context. ${ }^{5}$ This is followed by an interesting paper that reports how there is consensus around the components of a quality computerised medical record system. Interestingly the components include communication with patients and enhancing their quality of life; ${ }^{6}$ these aspirations might eventually include substituting functions carried out by the family doctor.

The leading article, in this issue, reports how we need to learn how to make much more rigorous use of real-world evidence (RWE). ${ }^{7}$ The large amount of data within computerised systems is under used; however, if we are going to make better use of it we need to define what generates good RWE. The key element of rigorous RWE should include:

- The discipline of good research questions before the investigation starts;

- To define the real world data set(s) to be used;

- To develop smarter and more rigorous analytics.

Our final paper, in this issue, reports how usability was the biggest barrier to the adoption of a computerised decision support system for chronic disease management. ${ }^{8}$

\section{THE GRAND CHALLENGES TO BE OVERCOME IF WE ARE TO REPLACE DOCTORS' JUDGEMENT WITH COMPUTERS}

Your Editor asserts there are five grand challenges to be overcome if we are to meet the English Health Secretaries aspiration to replace doctors' judgement with computers.

1. Technology must be capable of being incorporated into clinical workflow. Over and over we hear about the challenges of usability and difficulties in incorporating technology into clinical workflow.

2. We need analytics that are able to make use of the wide range of data available. There is scope to greatly improve advanced analytics so that we can make better use of growing data volumes; so called 'Big data'.

3. Regulatory and legal compliance including ethics and privacy. These can be enormous barriers to introducing technology. The e-prescribing paper from Canada is a good example for this. ${ }^{5}$

4. Business models that fund the introduction of effective and more efficient change. So often we see technologies, like the self-service kiosk developed, but they are never adopted because there is a lack of a business processes or reimbursement models to support this.

5. Services (computerised or otherwise) that identify additional cases/people with a risk factor will often result in increased health service expenditure. The English Health Secretary's comments come at a time when the English National Health Service is trying to move to seven-day working at a time when it faces a large deficit. ${ }^{9}$ Regrettably, readily available technologies that find new cases are likely to increase rather than decrease demand and health system costs.

\section{SUMMARY}

Informatics is a discipline that is being looked towards to solve major health challenges. In informatics, we will continue to innovate and gradually augment, support and sometimes substitute computers for doctors' judgement.

4. Wrenn G, Syed I and Kasiah F. Using a self-service kiosk to identify behavioural health needs in a primary care clinic serving an urban, underserved population. Journal of Innovation in Health Informatics 2015;22(3):323-8. Available from: http:// dx.doi.org/10.14236/jhi.v22i3.134.

5. Gagnon M-P, Payne-Gagnon J, Sicotte C, Langué-Dubé J-A and Motulsky A. Connecting primary care clinics and community pharmacies through a nationwide electronic prescribing network: a qualitative study. Journal of Innovation in Health Informatics 2015;22(3):359-67. Available from: http://dx.doi. org/10.14236/jhi.v22i3.168.

6. Kralj D, Kern J, Tonković S and Končar M. Development of the quality assessment model of EHR software in family medicine practices: research based on user satisfaction. Journal of Innovation in Health Informatics 2015;22(3):340-58. Available from: http://dx.doi.org/10.14236/jhi.v22i3.158. 
7. de Lusignan S, Crawford L and Munro N. Creating and using real world evidence to answer questions about clinical effectiveness. Journal of Innovation in Health Informatics 2015;22(3):368-73. http://dx.doi.org/10.14236/jhi.v22i3.177.

8. Nair K, Malaeekeh R, Schabort I, Taenzer P, Radhakrishnan A and Guenter D. A clinical decision support system for chronic pain management in primary care: usability testing and its relevance.
Journal of Innovation in Health Informatics 2015;22(3):329-32. Available from: http://dx.doi.org/10.14236/jhi.v22i3.149.

9. Campbell D and Weaver M. NHS England chief: cash shortages could hit plans for seven-day health service. The Guardian $15^{\text {th }}$ May 2015. Available from: http://www.theguardian.com/society/2015/may/18/health-unions-threaten-to-strike-if-seven-daynhs-means-pay-cuts. 